\title{
Yang's Dynamic Vertical Balance Process for the Content of Cd in a Marine Bay
}

\author{
Dongfang Yang1,2*, Sivakumar Manickam³, Danfeng Yang", Sixi Zhu1, Ming Wang1 \\ ${ }^{1}$ College of Chemistry and Environmental Science, Guizhou Minzu University, Guiyang, China \\ ${ }^{2}$ North China Sea Environmental Monitoring Center, SOA, Qingdao, China \\ ${ }^{3}$ Department of Chemical and Environmental Engineering, Faculty of Science and Engineering, University \\ of Nottingham Malaysia, Kuala Lumpur, Malaysia \\ ${ }^{4}$ The Fu Foundation School of Engineering and Applied Science, Columbia University, New York City, New York, USA \\ Email: *dfyang_dfyang@126.com
}

How to cite this paper: Yang, D. F., Manickam, S., Yang, D. F., Zhu, S. X., \& Wang, M. (2019). Yang's Dynamic Vertical Balance Process for the Content of $\mathrm{Cd}$ in a Marine Bay. Journal of Geoscience and Environment Protection, 7, 16-25.

https://doi.org/10.4236/gep.2019.75002

Received: March 4, 2019

Accepted: May 14, 2019

Published: May 17, 2019

\begin{abstract}
This study analyzes the horizontal and vertical migration processes of $\mathrm{Cd}$ contents based on the investigations conducted during May and August 1990. It reveals the dynamic balance process of $\mathrm{Cd}$ substance in a marine bay and shows that in the waters close to the source input, the content of $\mathrm{Cd}$ in the surface waters is the highest, and also the vertical dilution amount is the highest. This is the beginning of the dynamic vertical balance process. Along with distance from the source input, the sedimentation is an ongoing process, which results in a decrease in the content of $\mathrm{Cd}$ in the surface waters, and a reduction in the vertical dilution amount. This process continues to the balance point. In waters far away from the source input, the content of $\mathrm{Cd}$ is homogeneous in the waters, and the vertical dilution amount decreases to the lowest value, i.e., the balance point. Furthermore, a block diagram has been provided to demonstrate the dynamic vertical balance process.
\end{abstract}

\section{Keywords}

Cadmium, Balance, Dynamic, Process, Jiaozhou Bay

\section{Introduction}

With the rapid development of industries, many different discharges from the industries lead to massive pollution to the environment, especially the discharges of $\mathrm{Cd}, \mathrm{Pb}, \mathrm{Cr}$ into the soil and waters (Chen et al., 2014; Jin et al., 2013). The heavy metals $\mathrm{Cd}$ and $\mathrm{Cr}$, and its compounds are commonly applied in the industries for electroplating, dyeing, leather making and coatings (Xu et al., 2002), and thus after the production process, a large amount of wastewaters containing 
$\mathrm{Cd}$ and $\mathrm{Cr}$ is generated. Since the pollutants in the wastewaters could not be decomposed by themselves, they concentrate in the living bodies in the waters and soils, destroy the structure of the living things and threaten the human health by the food chain (Cheng, 2012). For example, Cd as a heavy metal enters plants and accumulates enough to cause poisoning (Shaan et al., 2009). The pollution of $\mathrm{Cd}$ results in breaking the structures of the cells, inhibiting the photosynthesis, weakening the uptake of water and nutrients in the vegetables such as pepper, cucumber, cauliflower, tomato, cabbage, rape, etc. (Li et al., 2005; Peng et al., 2006; Tang et al., 2008; Meral \& Gomez, 1994). Also, Cd and Cr have dangerous health effects such as teratogenic, mutagenic, and carcinogenic diseases (Zhong et al., 2012; Wang et al., 2013).

Artificial wetland simulates the natural wetland systems using the interaction among different animals, plants, microorganisms, and inorganic environment to load some pollutants, by the functions of physical uptake, filtration, and settlement, and chemical oxidation, decomposition, and biodegradation resulting in the purification of wastewater (Liu et al., 2012). Compared with the natural wetland system, the artificial wetland has the positive function of purifying the wastewater (Zhu et al., 2010), such that under the threat of Cr different plants show different characteristics of physiology and biochemistry and the growth response (Zhu et al., 2014a, 2014b, 2014c; Zhao et al., 2017), and Cd concentrates in the plants (Zhang \& Chen, 2013). Therefore, these methods provide the scientific grounds for the renovation of plants for $\mathrm{Cr}$ and $\mathrm{Cd}$ pollution.

Along with rapid economic growth and industrial development, a large amount of generated wastes are discharged to the environment (Yang et al., 2010a, 2010b, 2010c, 2013, 2014a, 2014b). The ocean is a sink as various pollutants are discharged to the ocean via many different paths such as river discharges, atmospheric deposition, marine traffic, etc. (Yang et al., 2014c, 2015a, 2015b, 2015c). These pollutants move through the water body and finally reach to the bottom of the sea through the effect of water (Yang et al., 2015d, 2016a, 2016b, 2016c, 2016d). Understanding the migration process of substances in the marine bay is essential to environmental protection and remediation. Jiaozhou Bay is a semi-closed bay located in Shandong Province, China. This bay is surrounded by the cities of Qingdao, Jiaozhou and Jiaonan. The industrial developments and hence the economy is rapidly growing since the 1980s which intensified the environmental pollution problems, but yet efficient waste treatment processes are lacking (Yang et al., 2016e, 2016f, 2016g, 2016h, 2016i, 2016j, 2017a, 2017b, 2017c, 2017d, 2017e). Cd is widely used in various industries, yet $\mathrm{Cd}$ is highly toxic, and its existence in excess in the environment could result in health risks (Yang et al., 2017f, 2017g, 2017h, 2017i, 2017j, 2018). On this context, investigations were attempted on Cd in May and August 1990, to analyze the horizontal and vertical migration processes of $\mathrm{Cd}$, to reveal the dynamic balance process. Overall, this study provides a scientific basis on the migration process of pollutants in a marine bay. 


\section{Materials and Methods}

Study area: Jiaozhou Bay $\left(120^{\circ} 04^{\prime}-120^{\circ} 23^{\prime} \mathrm{E}, 35^{\circ} 55^{\prime}-36^{\circ} 18^{\prime} \mathrm{N}\right)$ is located in the south of Shandong Province, eastern China (Figure 1). It is a semi-closed bay with the total area, average water depth and bay mouth width of $446 \mathrm{~km}^{2}, 7$ $\mathrm{m}$, and $3 \mathrm{~km}$, respectively. There are more than ten inflow rivers such as Haibo River, Licun River and Loushan River (Yang et al., 2005, 2014).

Data source: The data were provided by the North China Sea Environmental Monitoring Center. The investigations were conducted in May and August 1990. Surface and bottom water samples from 2 sampling sites (i.e., 55 and 60) were collected and measured by following the standards of National Specification for Marine Monitoring (Figure 1) (China's State Oceanic Administration, 1991).

Modeling for horizontal loss: The contents of the substances in the marine bay waters change continuously owing to an exchange between open and internal waters in the bay (Yang et al., 2016d, 2016e, 2016f, 2016g). Site 55 is located in the bay center, while Site 66 is located in the bay mouth. It is considered that the contents of the substances in the surface and bottom waters in the bay center and the bay mouth are, $A$ and $a$, and $B$ and $b$, respectively.

In the surface waters, and from the bay center to the bay mouth, the migration process is calculated using the following Equation (1).

$$
D=(A-B), E=(100 \times|A-B| / \max (A, B)) \%
$$

where $D$ is the horizontal absolute loss amount in surface waters, and $E$ is the horizontal relative loss amount.

In the bottom waters, and from the bay center to the bay mouth, the migration process is calculated using the following Equation (2).

$$
d=(a-b), e=(100 \times|a-b| / \max (a, b)) \%
$$

where $d$ is the horizontal absolute loss amount in the surface waters, and $e$ is the horizontal relative loss amount.

Modeling for vertical loss: It is assumed that the contents of the substances in the surface and bottom waters in a specific sampling site (e.g., Site 55 in the bay center) are $A$ and a, respectively. From the surface waters to bottom waters, the migration process is calculated using the following Equation (3).

$$
V_{n a}=(A-a), V_{n r}=(100 \times|A-a| / \max (A, a)) \%
$$

where $V_{n a}$ is the horizontal absolute dilution amount from the surface waters to bottom waters, $V_{n r}$ is the horizontal relative dilution amount. While from the bottom waters to surface waters, $V_{n a}$ refers to the horizontal absolute accumulation amount, and $V_{n r}$ refers to the horizontal relative accumulation amount.

\section{Results}

Horizontal change: The horizontal migration process of $\mathrm{Cd}$ in the surface waters in Jiaozhou Bay was calculated based on Cd contents in Site 55 in the bay center and Site 66 in the bay mouth. The horizontal migration process of $\mathrm{Cd}$ in 


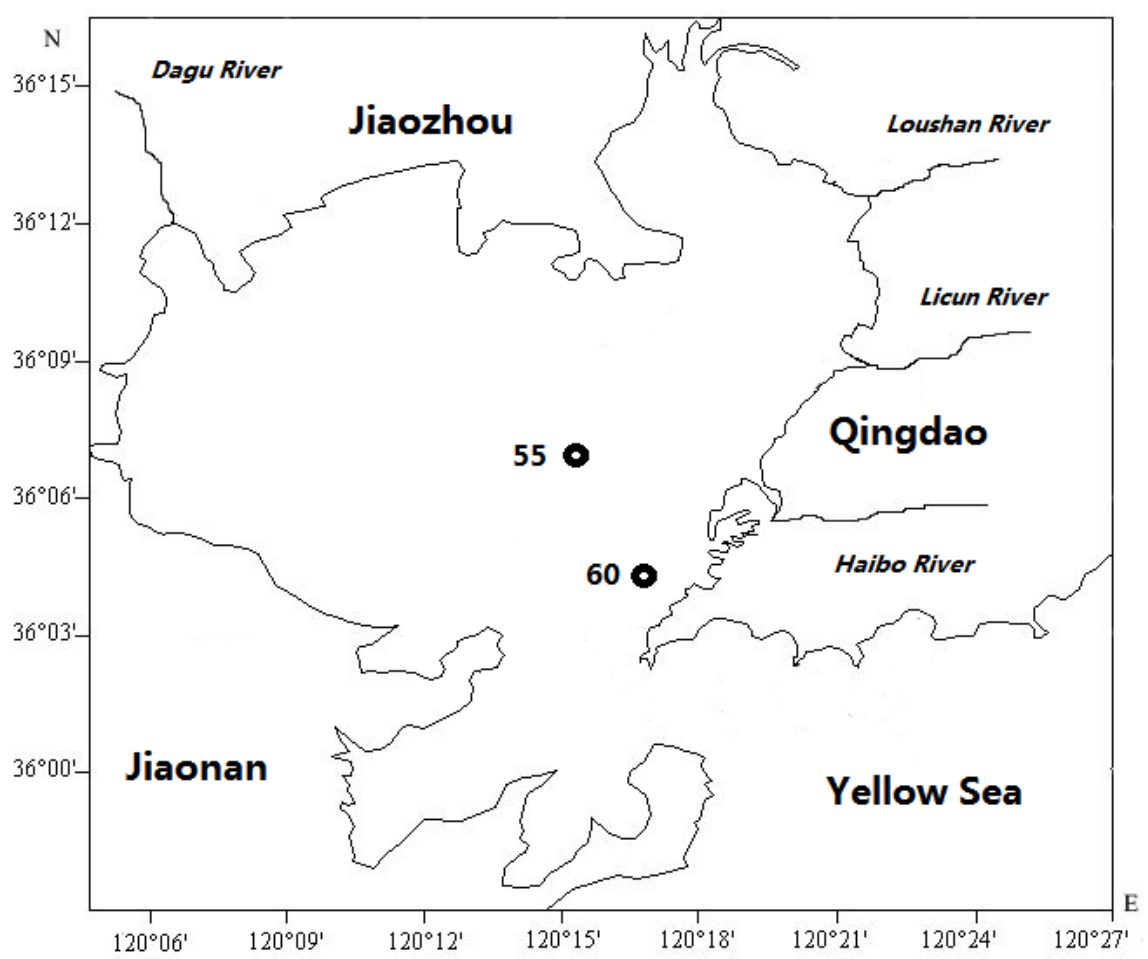

Figure 1. Geographical location and the monitoring sites in Jiaozhou Bay.

the bottom waters in Jiaozhou Bay was calculated according to Cd contents in Site 55 in the bay center and Site 66 in the inner side of the bay mouth. The horizontal losses of $\mathrm{Cd}$ in the surface and bottom waters have been calculated as shown in Table 1.

Vertical change: The vertical migration process of $\mathrm{Cd}$ in the waters in Jiaozhou Bay was calculated according to Cd contents in Site 55 in the bay center and Site 66 in the bay mouth. The horizontal losses of Cd have been calculated as shown in Table 2.

\section{Discussion}

Vertical and horizontal losses: The vertical and horizontal losses during the migration process of substances in the marine bay were determined by the source input and vertical and horizontal effect of water (Yang et al., 2017d, 2017e, 2017f) The primary source of Cd in May 1990 was marine traffic (i.e., the wharf in the north of bay mouth) whose source strength was relatively weak $\left(1.02 \mu \mathrm{g} \cdot \mathrm{L}^{-1}\right)$. In May 1990, from the bay mouth to the bay center the horizontal loss in the surface waters was $65.68 \%$, while from the bay center to the bay mouth the horizontal loss in the bottom waters was $68.57 \%$ (Figure 2). Once Cd moved across the bay waters, irrespective of whether it is from the bay mouth to the bay center or from the bay center to the bay mouth, the amount of horizontal loss in May 1990 was relatively high (65.68\% to 68.57\%). In May 1990, for vertical changes, both the vertical dilution and accumulation amounts in the bay center were $0 \%$, while in the bay mouth there was a vertical dilution process and 
Table 1. Horizontal losses of Cd from Site 55 to Site 66 in Jiaozhou Bay.

\begin{tabular}{ccccc}
\hline \multirow{2}{*}{ Month } & \multicolumn{2}{c}{ Surface waters } & \multicolumn{2}{c}{ Bottom waters } \\
\cline { 2 - 5 } & $D / \mu \mathrm{g} \cdot \mathrm{L}^{-1}$ & $E / \%$ & $d / \mu \mathrm{g} \cdot \mathrm{L}^{-1}$ & $e / \%$ \\
\hline May & -0.67 & 65.68 & 0.24 & 68.57 \\
August & 1.04 & 82.53 & 0.30 & 62.50 \\
\hline
\end{tabular}

Table 2. Vertical losses of Cd from Site 55 to Site 66 in Jiaozhou Bay.

\begin{tabular}{cccc}
\hline Month & Site & $V_{n a} / \mu \mathrm{g} \cdot \mathrm{L}^{-1}$ & $V_{n r} / \%$ \\
\hline \multirow{2}{*}{ May } & 55 & 0.00 & 0.00 \\
& 66 & 0.91 & 89.21 \\
\multirow{2}{*}{ August } & 55 & 0.78 & 61.90 \\
& 66 & 0.04 & 18.18 \\
\hline
\end{tabular}

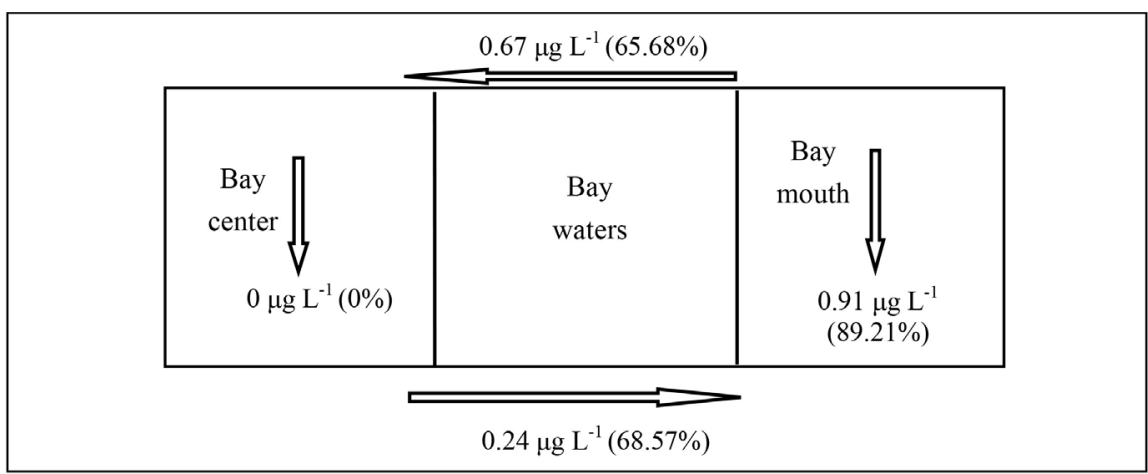

Figure 2. Block diagram demonstrating the horizontal-vertical changes of Cd in Jiaozhou Bay (in May 1990).

its vertical dilution amount was $89.21 \%$ (Figure 2). This demonstrates that there was rapid sedimentation in the north of the bay mouth where marine traffic was the significant source input (i.e., the wharf), while in the bay center which was far away from the source input there was little sedimentation.

The primary source of Cd in August 1990 was atmospheric deposition whose source strength was relatively strong $\left(1.26 \mu \mathrm{g} \cdot \mathrm{L}^{-1}\right)$. In August 1990, from the bay mouth to the bay center the horizontal loss in the surface waters was $82.53 \%$, compared to $62.50 \%$ in the bottom waters (Figure 3). Once Cd moved across the bay waters from the bay center to the bay mouth, the amounts of horizontal loss in August 1990 were relatively high (62.50\% to 82.53\%). In May 1990, for vertical changes, both the vertical dilution and accumulation amounts in the bay center were $0 \%$, while in the bay mouth there was a vertical dilution process whose vertical dilution amount was $89.21 \%$ (Figure 2). This indicates that there was rapid sedimentation in the north of the bay mouth where marine traffic was the significant source input (i.e., the wharf), while in the bay center which was far away from the source input there was little sedimentation. 


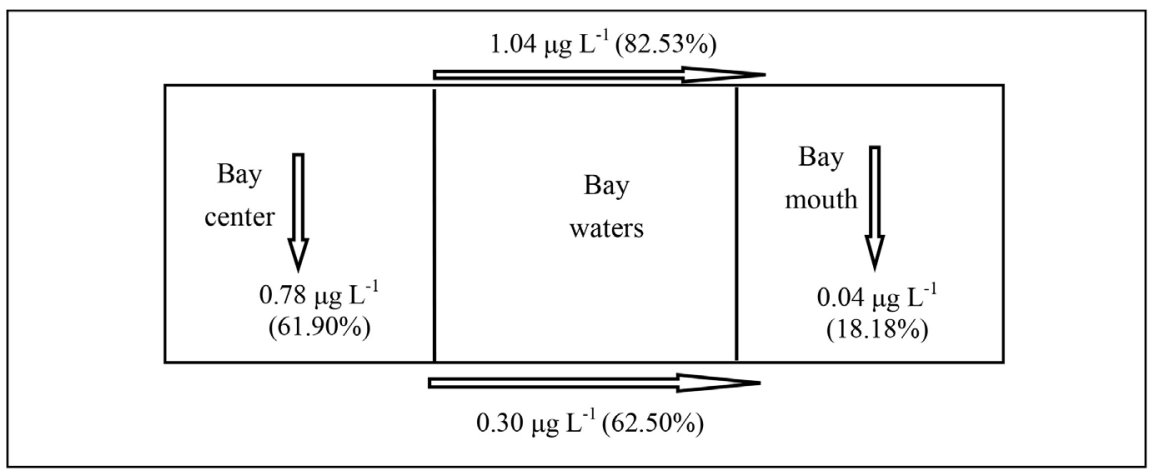

Figure 3. Block diagram signifying the horizontal-vertical changes of Cd in Jiaozhou Bay (in August 1990).

Dynamic vertical balance: The vertical and horizontal losses during the migration process of substances in the marine bay were determined by source input and vertical and horizontal effect of water (Yang et al., 2017d, 2017e, 2017f). It could be concluded that once substances move across the bay waters, irrespective of whether they are from the bay mouth to the bay center or from the bay center to the bay mouth, the amounts of horizontal loss in different seasons were relatively high. For vertical changes, there was rapid sedimentation in the waters that were close to the major source input, while in the bay mouth that was far away from the source input there was little sedimentation.

The above phenomenon exhibits the dynamic vertical balance of substances in the marine bay. In waters that were close to the source input, the content of substances in the surface waters is the highest, and the vertical dilution amount is also the highest. This shows the beginning of the dynamic vertical balance process. Along with distance from the source input, the sedimentation is ongoing which results in a decrease in the content of substances in the surface waters, and a decrease in the vertical dilution amount. This process continues to the balance point. In waters far away from the source input, the content of substances is homogeneous in the waters, and the vertical dilution amount decreases to the lowest value, i.e., to the balance point. This dynamic vertical balance process has been demonstrated as shown in the block diagram (Figure 4).

\section{Conclusion}

The horizontal and vertical migration processes of Cd contents were analyzed, and the dynamic balance process was revealed. At the starting point, in the waters close to the source input, the content of substances in the surface waters was the highest, and the vertical dilution amount is also the highest. In the case of balancing process, along with the distance from the source input, the sedimentation is an ongoing process which results into a decrease in the content of substances in the surface waters, and a decrease in the vertical dilution amount. Whereas at the end point, in the waters far away from the source input, the content of substances is homogeneous in the waters, and the vertical dilution 


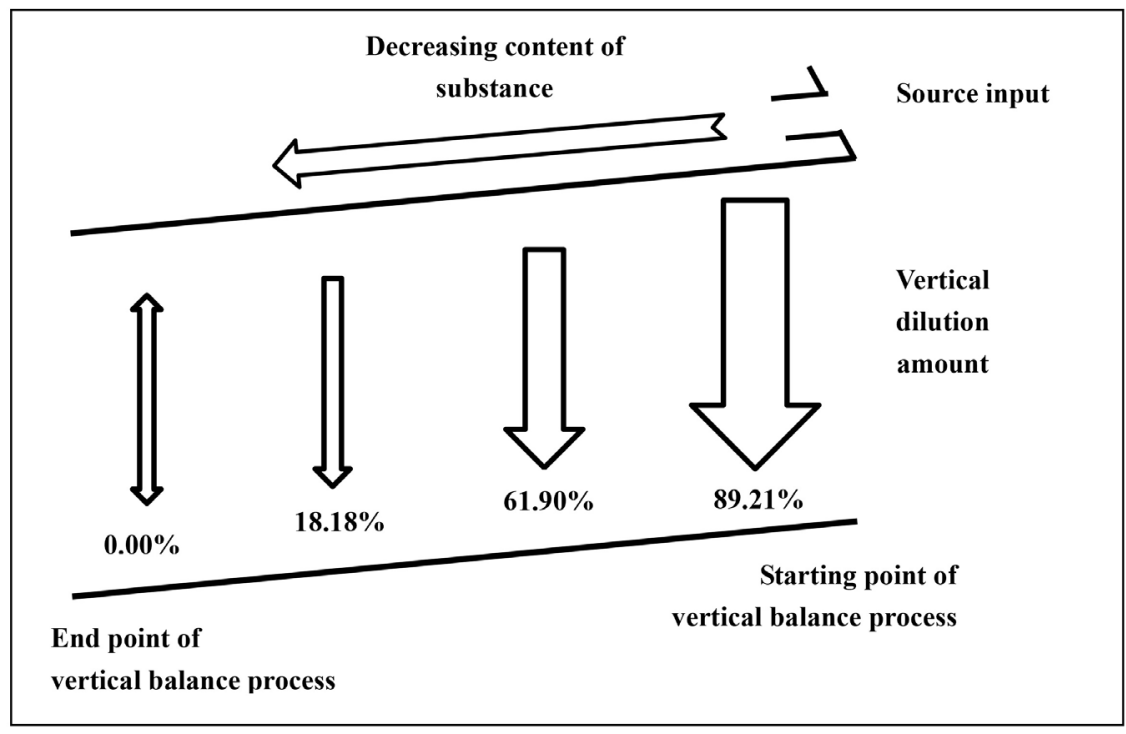

Figure 4. Block diagram illustrating the dynamic vertical balance process of substances in a marine bay.

amount decreased to the lowest value, i.e., to the balance point. Finally, this dynamic vertical balance process has been demonstrated using a block diagram.

\section{Acknowledgements}

This research was sponsored by Doctoral Degree Construction Library of Guizhou Nationalities University, Research Projects of Guizhou Nationalities University ([2014]02), Research Projects of Guizhou Province Ministry of Education (KY [2014] 266) and Research Projects of Guizhou Province Ministry of Science and Technology (LH [2014] 7376).

\section{Conflicts of Interest}

The authors declare no conflicts of interest regarding the publication of this paper.

\section{References}

Chen, Y., Yang, J. L., \& Ling, M. (2014). A Review on Waste Water Including $\mathrm{Cr}^{6+}$ Handled by Technology. Technology and Company, 22, 146-146.

Cheng, J. (2012). The Sewage Treatment by Constructed Wetland and Its Application Development in China. Construction of Shanxi, 38, 140-141.

China's State Oceanic Administration (1991). The Specification for Marine Monitoring (pp. 1-300). Beijing: Ocean Press.

Jin, L. F., Yuan, L. M., Hu, W. R. et al. (2013). The Advance of Mechanism and Toxicological Effect on the Cell Including $\mathrm{Cr}^{6+}$. Journal of Chinese Cell Biology, 35, 387-392.

Li, D. M., Zhu, Z. J., Liu, Y. H. et al. (2005). The Effect of Cd on Photosynthesis of Pakchoi. Journal of Zhejiang University, 31, 459-464.

Liu, D., Xu, W., Jie, C. et al. (2012). Constructed Wetlands as Biofuel Production Systems. Nature Climate Change, 2, 190-194. https://doi.org/10.1038/nclimate1370 
Meral, R., \& Gomez, I. (1994). Effect of Cadmium on Nutrient Distribution, Yield and Growth of Tomato Grown in Soils Culture. Journal of Plant Nutrition, 17, 953-962. https://doi.org/10.1080/01904169409364780

Peng, W. Z., Wang, K. Q., Hu, D. et al. (2006). The Distribution Laws of Cd in Vivo of the Cucumber Plants and the Effect of Cd on Its Growth. Journal of Agricultural Environmental Sciences, 25, 92-95.

Shaan, H., Li, S. T., Lui, R. L. et al. (2009). The Effect and Mechanism of the Cd Soil on Straw and Pig Manure. Journal of Nuclear Agricultural Sciences, 23, 139-144.

Tang, H. H., Yang, T., Hu, H. Y. et al. (2008). The Effect of Cd on the Photosynthesis of Cauliflower and Cd's Distribution in It. Acta Horticulturae Sinica, 35, 1291-1296.

Wang, Q., Li, Y., Sun, P. et al. (2013). The Advanced Development on Waste Water Including Cr Handled by Technology. Environment Science and Technology, 36, 150-156.

Xu, Q. S., Shi, G. X., Du, K. X. et al. (2002). The Effect of the $\mathrm{Cr}^{6+}$ Pollution on Physiological, Biochemical and Cellular Ultrastructure of the Waterfront Blade. Plant of Guangxi, 22, 92-96.

Yang, D. F., \& Gao, Z. H. (2010b). Marine Bay Ecology (II) (pp. 1-330). Beijing: Ocean Press.

Yang, D. F., \& Miao, Z. Q. (2010a). Marine Bay Ecology (I) (pp. 1-320). Beijing: Ocean Press.

Yang, D. F., Chen, S. T., Li, B. L. et al. (2015c). Research on the Vertical Distribution of Cadmium in Jiaozhou Bay Waters. Proceedings of the 2015 International Symposium on Computers and Informatics, 2667-2674. https://doi.org/10.2991/isci-15.2015.346

Yang, D. F., Chen, Y., Gao, Z. H. et al. (2005). Silicon Limitation on Primary Production and Its Destiny in Jiaozhou Bay, China IV Transect Offshore the Coast with Estuaries. Chinese Journal of Oceanology and Limnology, 23, 72-90.

Yang, D. F., Chen, Y., Liu, C. X. et al. (2013). The Transfer Process and Background Value Structure of Cadmium in Jiaozhou Bay. Coastal Engineering, 32, 68-78.

Yang, D. F., Chen, Y., Wang, H. et al. (2010c). Coastal Engineering (Vol. 29, pp. 73-82).

Yang, D. F., Li, H. X., Zhang, X. L. et al. (2017f). The Back and Forth Transformation between Homogeneity and Heterogeneity of Cd in Marine Bay. Advances in Engineering Research, 138, 847-850. https://doi.org/10.2991/mecs-17.2017.153

Yang, D. F., Li, H. X., Zhang, X. L. et al. (2018). Spatial-Temporal Migration Laws of Cd in Jiaozhou Bay. Earth and Environment Science, 133, 1-4. https://doi.org/10.1088/1755-1315/113/1/012129

Yang, D. F., Miao, Z. Q., Li, G. X. et al. (2017g). Different Stages of Cd's Transporting Process in Waters in Jiaozhou Bay. Earth and Environment Science, 81, 1-6. https://doi.org/10.1088/1755-1315/81/1/012094

Yang, D. F., Qu, X. C., Chen, Y. et al. (2016e). Sedimentation Mechanism of Cd in Jiaozhou Bay Waters. Advances in Engineering Research, 80, 993-997. https://doi.org/10.2991/icamcs-16.2016.201

Yang, D. F., Wang, F. Y., Gao, Z. H. et al. (2004). The Ecological Phenomenon of the Phytoplankton in Jiaozhou Bay. Marine Science, 28, 71-74.

Yang, D. F., Wang, F. Y., Sun, Z. H. et al. (2015d). Research on Vertical Distribution and Settling Process of Cd in Jiaozhou Bay. Advances in Engineering Research, 40, 776-781. https://doi.org/10.2991/ifeesm-15.2015.144

Yang, D. F., Wang, F. Y., Wu, F. Y. et al. (2014b). The Structure of Environmental Back- 
ground Value of Cadmium in Jiaozhou Bay Waters. Applied Mechanics and Materials, 644-650, 5329-5312.

Yang, D. F., Wang, F. Y., Yang, X. Q. et al. (2016a). Cadmium Background Pollution in Jiaozhou Bay. Advances in Engineering Research, 60, 1347-1350. https://doi.org/10.2991/icmmct-16.2016.265

Yang, D. F., Wang, F. Y., Zhu, S X. et al. (2017e). The Influence of River on Cd Contents in Jiaozhou Bay. World Scientific Research Journal, 3, 1-5.

Yang, D. F., Wang, F. Y., Zhu, S. X. et al. (2016d). Homogeneity of Cd Contents in Jiaozhou Bay Waters. Advances in Engineering Research, 65, 298-302. https://doi.org/10.2991/i3csee-16.2016.57

Yang, D. F., Wang, F. Y., Zhu, S. X. et al. (2016h). The Influence of Marine Current to Cd in Jiaozhou Bay. World Scientific Research Journal, 2, 38-42.

Yang, D. F., Wang, F. Y., Zhu, S. X. et al. (2017b). Three Different Types of Cd Content's Modes. Computer Life, 5, 1-7.

Yang, D. F., Wang, F. Y., Zhu, S. X. et al. (2017d). Horizontal Loss Rate Patterns of Cu Content in Marine Bay. Computer Life, 5, 91-95.

Yang, D. F., Wang, Q., Wang, M. et al. (2017j). Annual Changes and Seasonal Variations of Cd in Jiaozhou Bay 1979-1983. Advances in Engineering Research, 141, 1587-1590. https://doi.org/10.2991/icmmcce-17.2017.279

Yang, D. F., Wang, Q., Wang, Z. K. et al. (2017h). The Changes of Cd Sources in Jiaozhou Bay 1979-1983. Earth and Environment Science, 81, 1-4. https://doi.org/10.1088/1755-1315/81/1/012095

Yang, D. F., Wang, Z. K., Su, C. H. et al. (2017c). Sedimentation Process and Mechanism of Cd in Jiaozhou Bay. Advances in Engineering Research, 123, 1477-1480. https://doi.org/10.2991/msmee-17.2017.267

Yang, D. F., Wei, L. Z., Feng, M. et al. (2017i). Transport Process and Block Diagram of Cd in Jiaozhou Bay. Earth and Environment Science, 81, 1-5. https://doi.org/10.1088/1755-1315/81/1/012096

Yang, D. F., Yang, D. F., Zhu, S. X. et al. (2016b). Spatial-Temporal Variations of Cd in Jiaozhou Bay. Advances in Engineering Research, 60, 403-407.

https://doi.org/10.2991/icmmct-16.2016.82

Yang, D. F., Yang, D. F., Zhu, S. X. et al. (2016f). Sedimentation Process and Vertical Distribution of Cd in Jiaozhou Bay. Advances in Engineering Research, 80, 998-1002. https://doi.org/10.2991/icamcs-16.2016.202

Yang, D. F., Yang, D. F., Zhu, S. X. et al. (2016j). Transfer Process of Cd in the Bay Mouth of Jiaozhou Bay. Journal of Computing and Electronic Information Management, 3, 467-474.

Yang, D. F., Yang, X. Q., Wang, M. et al. (2016c). The Slight Impacts of Marine Current to Cd Contents in Bottom Waters in Jiaozhou Bay. Advances in Engineering Research, 60, 412-415. https://doi.org/10.2991/icmmct-16.2016.84

Yang, D. F., Zhu, S X., Wang, M. et al. (2016i). High Settling Process of Cd in Jiaozhou Bay. International Core Journal of Engineering, 2, 1-4.

Yang, D. F., Zhu, S. X., Wang, F. Y. et al. (2015b). Distribution and Aggregation Process of Cd in Jiaozhou Bay. Advances in Computer Science Research, 194-197.

Yang, D. F., Zhu, S. X., Wang, Z. K. et al. (2016g). Spatial-Temporal Changes of Cd in Jiaozhou Bay. Computer Life, 4, 446-450.

Yang, D. F., Zhu, S. X., Wang, Z. K. et al. (2017a). Dynamic Change of Cd's Sedimenta- 
tion Process in Jiaozhou Bay. Journal of Computing and Electronic Information Management, 4, 1-9.

Yang, D. F., Zhu, S. X., Wu, F. Y. et al. (2014c). Study on the Cadmium in Surface Waters in Jiaozhou Bay. IEEE Workshop on Advanced Research and Technology Industry Applications, 1012-1014.

Yang, D. F., Zhu, S. X., Wu, Y. F. et al. (2014a). The Distribution and Source of Cadmium in Jiaozhou Bay. Applied Mechanics and Materials, 644-650, 5325-5328.

Yang, D. F., Zhu, S. X., Yang, X. Q. et al. (2015a). Pollution Level and Sources of Cd in Jiaozhou Bay. Materials Engineering and Information Technology Application, 558-561.

Zhang, C. X., \& Chen, W. F. (2013). Ecophysiological Responses and Accumulation Characteristics of Iris Germanica to Cd Stress. Journal of Ecology, 33, 2165-2172.

Zhao, B., Zhu, S. X., Xu, C. et al. (2017). Chromium Accumulation and Ecological Characters of Canna under Chromium Stress. Science Technology and Engineering, 17, 44-49.

Zhong, L., Zheng, L., Ding, A. Z. et al. (2012). The Treatment of Pollution River in China by Constructed Wetland and Statistical Analysis of Its Effectiveness. Journal of Beijing Normal University, 48, 66-67.

Zhu, S. X., Ge, H. L., Ge, Y. et al. (2010). Effects of Plant Diversity on Productivity and Substrate Nitrogen in a Subsurface Vertical Flow Constructed Wetland. Ecological Engineering, 36, 1307-1313. https://doi.org/10.1016/j.ecoleng.2010.06.007

Zhu, S. X., Wang, F Y., Liu, W. et al. (2014c). Characters of Plant Growth, Cr Accumulation and Its Subcellular Distribution in Thalia Dealbata under Cr Stress. Environment Science and Technology, 34, 30-31.

Zhu, S. X., Wang, F. Y., Yang, X. Q. et al. (2014a). Effects of Traditional Chinese Medicine Wastewater Treatment on the Physiological and Biochemical Index. Acta Agriculturae Boreali-Occidentalis Sinica, 5, 153-157.

Zhu, S. X., Wang, F. Y., Yang, X. Q. et al. (2014b). Effects of Wastewater of Traditional Chinese Medicine on Physiological and Biochemical Characteristics of Thalia Dealbata. Hubei Agricultural Sciences, 53, 3070-3071. 